\title{
T-cell recognition of chemicals, protein allergens and drugs: towards the development of in vitro assays
}

\author{
Stefan F. Martin · Philipp R. Esser • Sonja Schmucker • Lisa Dietz • Dean J. Naisbitt • B. Kevin Park • \\ Marc Vocanson - Jean-Francois Nicolas • Monika Keller • Werner J. Pichler • Matthias Peiser • \\ Andreas Luch • Reinhard Wanner • Enrico Maggi • Andrea Cavani - Thomas Rustemeyer • \\ Anne Richter $\cdot$ Hermann-Josef Thierse $\cdot$ Federica Sallusto
}

Received: 22 April 2010/Revised: 23 July 2010/Accepted: 30 July 2010/Published online: 18 August 2010

(C) Springer Basel AG 2010

\begin{abstract}
Chemicals can elicit T-cell-mediated diseases such as allergic contact dermatitis and adverse drug reactions. Therefore, testing of chemicals, drugs and protein allergens for hazard identification and risk assessment is essential in regulatory toxicology. The seventh amendment of the EU Cosmetics Directive now prohibits the testing of cosmetic ingredients in mice, guinea pigs and other animal
\end{abstract}

This article is dedicated to the memory of our colleague and friend Reinhard Wanner, died 2 April 2010.

S. F. Martin $(\bowtie) \cdot$ P. R. Esser

Allergy Research Group, Department of Dermatology,

University Medical Center Freiburg, Hauptstrasse 7,

79104 Freiburg, Germany

e-mail: stefan.martin@uniklinik-freiburg.de

P. R. Esser

Faculty of Biology, University of Freiburg, Freiburg, Germany

S. Schmucker · A. Richter

Miltenyi Biotec GmbH, Bergisch Gladbach, Germany

L. Dietz · H.-J. Thierse

Research Group for Immunology and Proteomics,

Department of Dermatology and University Medical Center

Mannheim, University of Heidelberg, Mannheim, Germany

D. J. Naisbitt · B. K. Park

Department of Pharmacology, MRC Centre for Drug Safety

Science, University of Liverpool, Liverpool, UK

M. Vocanson · J.-F. Nicolas

Faculté de Médecine Lyon-Sud, INSERM U851,

Université de Lyon1, Lyon, France

M. Keller · W. J. Pichler

Division of Allergology, Clinic of Rheumatology and Clinical Immunology/Allergology, Inselspital, University Hospital and

University of Bern, Bern, Switzerland species to assess their sensitizing potential. In addition, the EU Chemicals Directive REACh requires the retesting of more than 30,000 chemicals for different toxicological endpoints, including sensitization, requiring vast numbers of animals. Therefore, alternative methods are urgently needed to eventually replace animal testing. Here, we summarize the outcome of an expert meeting in Rome on 7 November 2009 on the development of T-cell-based in vitro assays as tools in immunotoxicology to identify hazardous chemicals and drugs. In addition, we provide an

M. Peiser · A. Luch

BfR-Federal Institute for Risk Assessment, Berlin, Germany

R. Wanner

Institute of Molecular Biology and Bioinformatics, Charité,

Berlin, Germany

E. Maggi

Immunoallergology Unit, Policlinico di Careggi,

Department of Internal Medicine, University of Florence,

Florence, Italy

A. Cavani

Laboratory of Immunology, Istituto Dermopatico

dell'Immacolata-Istituto di Ricovero e Cura a Carattere

Scientifico, Rome, Italy

T. Rustemeyer

Department of Dermatology, VU Medical Center, Amsterdam,

The Netherlands

F. Sallusto

Institute for Research in Biomedicine, Bellinzona, Switzerland 
overview of the development of the field over the last two decades.

Keywords Allergy - Contact dermatitis . Drug hypersensitivity $\cdot \mathrm{T}$ cell $\cdot$ Immunotoxicology . In vitro alternatives $\cdot$ Non-animal testing $\cdot$ Bioassay

$\begin{array}{ll}\text { Abbreviations } \\ \text { ACD } & \text { Allergic contact dermatitis } \\ \text { ADR } & \text { Adverse drug reaction } \\ \text { APC } & \text { Antigen presenting cell } \\ \text { BB } & \text { Bandrowski's base } \\ \text { DC } & \text { Dendritic cell } \\ \text { DNCB } & \text { 2,4-Dinitrochlorobenzene } \\ \text { FITC } & \text { Fluorescein isothiocyanate } \\ \text { HSA } & \text { Human serum albumin } \\ \text { ICS } & \text { Intracellular cytokine staining } \\ \text { LC } & \text { Langerhans cell } \\ \text { LLNA } & \text { Local lymph node assay } \\ \text { LTT } & \text { Lymphocyte transformation test } \\ \text { moDC } & \text { Monocyte-derived dendritic cell } \\ \text { PBMC } & \text { Peripheral blood mononuclear cells } \\ \text { PPD } & \text { Para-phenylenediamine } \\ \text { TNBS } & \text { 2,4,6-Trinitrobenzene sulphonic acid } \\ \text { Treg } & \text { Regulatory T cell }\end{array}$

\section{Introduction}

Replacement of animal testing: $\mathrm{T}$ cells as tools in immunotoxicology

An expert meeting on " $\mathrm{T}$ cell recognition of chemicals, protein allergens and drugs: towards the development of in vitro assays", organized and chaired by Stefan F. Martin and Andrea Cavani and the EU project Sens-it-iv, was held on 7 November 2009, at the IDI-ICCRS in Rome. Participants from clinical and academic institutions discussed the state-of-the-art in order to promote further development of T-cell-based in vitro assays for the identification and detection of contact allergens, drugs and protein allergens. The outcome of this meeting is reported here. In addition, an overview of the efforts to induce chemical-specific $\mathrm{T}$ cells in vitro from the early 1990s up to today is given.

Efforts to replace animal testing: background

Identification of the sensitization potential of chemicals is mandatory to assure the safety of consumer products such as cosmetics, and efforts are being made worldwide to achieve this goal by the development of non-animal testing strategies. The development of in vitro alternatives to animal testing for the identification of contact allergens and drugs that cause adverse reactions and of protein allergens is necessary to reduce the large number of animals used in toxicology for safety assessment. The seventh amendment to the Cosmetics Directive of the European Union, which has been in effect since March 2009, prohibits the use of animals for sensitization testing of cosmetic ingredients [1]. Thus, the gold standard used for the identification of contact sensitizers, the local lymph node assay (LLNA) $[2,3]$, can no longer be used. The EU Chemicals Directive REACh would require a vast numbers of animals for retesting of more than 30,000 chemicals to assess their sensitizing potential [4-7]. International programmes have been established for the development of in vitro alternatives to animal testing in different areas of toxicology. In February 2008, a coalition of US governmental agencies, including the Environmental Protection Agency, the National Toxicology Program and the National Institutes of Health, signed a "Memorandum of Understanding" to develop and implement new methods in order to cease animal testing in the safety assessment of chemicals and drugs over a time frame of about 10 years $[8,9]$. The National Research Council committee report proposed a reasonable approach that includes in vivo testing in genetically engineered animal models to fill the gaps in knowledge $[8,10]$. This approach to future strategies in toxicology would enable cross-fertilization between the areas of basic science and non-animal testing that would result in a stepwise refinement of existing assays and development of new assays leading to a reduction and replacement of animal testing.

Traditionally, inherent toxicity of chemicals and drugs have been identified and characterized by injecting or gavaging compounds of interest into live animals and monitoring whether they are harmed or not. These in vivo assessment procedures are expensive, are time- and animalconsuming, are usually ethically questionable, and afford questionable results in terms of transferability to the human system [10]. In the US it has been estimated that there are about 10 million animals per year used in toxicity testing of chemicals and drugs including mice, rats, guinea pigs and other animals including dogs, cats and monkeys. In the EU, the overall usage of animals in research, regulation and diagnosis was about 12 million for the year 2005, of which approximately $8 \%$ (1.03 million) were subjected to toxicological safety studies sensu stricto [11].

These figures clearly demonstrate the need for alternatives to whole-animal testing considering the steadily growing number of new chemicals and drugs to be assessed for their potential adverse effects on human health. Although the US consortium aims at testing thousands of compounds in high-throughput formats by applying biochemical and human cell-based assays in conjunction with dose-response 
and extrapolation models, assessment of simple toxicity endpoints such as cytotoxicity, altered protein expression or DNA damage, along with computational toxicology (e.g. quantitative structure-activity relationships), mainly addresses acute adverse effects observed in single-dose testing, rather than subchronic or chronic toxicity. Overall, the replacement or refinement of in vivo acute toxicity testing is in pretty good shape due to extreme efforts in the past decades resulting in the establishment of a battery of alternatives accepted by the OECD and EU [10, 12-14]. So there are a number of in vitro methods and validated guidelines that allow the testing of dermal absorption, phototoxicity, skin irritation, skin and eye corrosion, acute oral toxicity and molecular endpoints such as mutagenicity. By contrast, reliable repeated-dose toxicity testing, that is detection of subchronic or chronic adverse effects, including endpoints such as allergenicity, carcinogenicity or teratogenicity, has so far turned out to be by far too complex to provide appropriately simple measurements in the test tube. Unfortunately, exactly these endpoints of repeated-dose toxicity are expected to require increasing numbers of animals in all industrial nations in the years to come.

In the context of the new EU Chemicals Directive REACh [15], there are estimates that about 40-50 million additional animals may be required to fulfil all related obligations for toxicological characterization and risk assessment of the socalled "existing chemicals" that entered the market before 1981 without appropriate safety evaluation prior to release. So, all of these chemicals, certainly far more than 30,000, need soon to be tested in a battery of assays mainly addressing subchronic and chronic endpoints, as well as their potency to induce sensitization and allergic contact dermatitis (ACD). In the characterization of adverse effects on the skin due to genotoxicity and sensitization, animal experiments still predominate. Currently, in the EU about 60,000 animals per year suffer in the testing of the sensitizing or irritating activities of chemicals alone (e.g. 22,184 guinea pigs and 21,350 mice in 2005). In response to the implementation of REACh, these numbers might considerably increase due to the lack of well-characterized and validated in vitro models for measuring a chemical's inherent allergenicity. Since established assays for evaluating this toxicological endpoint are extremely expensive, time-consuming and, most notably, painful for the creature treated, considerable effort is being applied to the development and validation of appropriate in vitro methods for sensitization testing, as explained in more detail below.

T-cell assays for the identification of contact allergens, hazardous drugs and protein allergens

Triggering of $\mathrm{T}$-cell responses to chemicals, drugs and protein allergens is the key event that decides whether initial sensitization that results in transient inflammation in the target organ will lead to manifest disease upon repeated contact with the chemical. Since many of the chemicals that we encounter everywhere in our daily life can cause T-cellmediated ACD, respiratory allergies or adverse drug reactions (ADR), there is a long-standing, and recently significantly growing interest in using $\mathrm{T}$ cells as tools in immunotoxicology for the identification of chemicals that cause such health risks. Other types of assays are in development and include peptide reactivity and single cellbased assays using, for example, human keratinocytes and dendritic cells (DC). They assess the activation of the innate immune system and of the antioxidant response which are hallmarks of the reactivity of such chemicals [16-23]. The innate immune response is essential for both the sensitization to the chemical and the subsequent adaptive T-cellmediated immune response upon further contacts [18-20]. In the single cell-based assays the sensitization potential of chemicals is tested by measuring, for example, chemicalinduced antioxidant responses [21, 22] or IL-18 production in keratinocytes [23] or the induction of activation markers such as CD86 on the cell surface of DC $[16,17]$.

Since $\mathrm{T}$ cells are the pathogenic effector cells in chemical-induced ACD, respiratory allergies or ADR, T-cell-based in vitro assays may be very useful to identify contact and respiratory allergens as well as hazardous drugs. They can be easily incorporated into tiered risk assessment strategies [16]. Protein-reactive small chemicals efficiently induce $\mathrm{T}$-cell responses and $\mathrm{B}$-cell responses, but the role of antibodies in the pathogenesis of ACD and ADR is not clear and is a matter of controversy. Therefore, assays based on B-cell responses to chemicals have not been developed. T-cell epitopes are generated efficiently via processing of chemically modified proteins by antigen-presenting cells (APC) such as DC to produce chemically modified peptides presented on MHC molecules to $\mathrm{T}$ cells or by direct modification of MHC-bound peptides. Our molecular understanding of the interaction of the T-cell receptor (TCR) with chemicals presented in the context of MHC molecules has significantly increased [2426]. We now know that some protein-reactive organic chemicals, classical haptens, are recognized by $\mathrm{T}$ cells as covalently hapten-modified MHC-bound peptides [27-32]. In contrast, metal ions such as nickel form noncovalent complexes with amino acids such as histidine in both MHC molecules and the TCR, sometimes also involving histidine residues in the peptide that is bound to the MHC molecule $[33,34]$. Furthermore, some organic chemicals may be recognized especially by effector and memory $\mathrm{T}$ cells without covalent binding to carrier peptides on MHC as formulated in the p-i concept (Fig. 1) [35-39].

T-cell-based in vitro assays should recapitulate key elements of the much more complex in vivo events that happen 


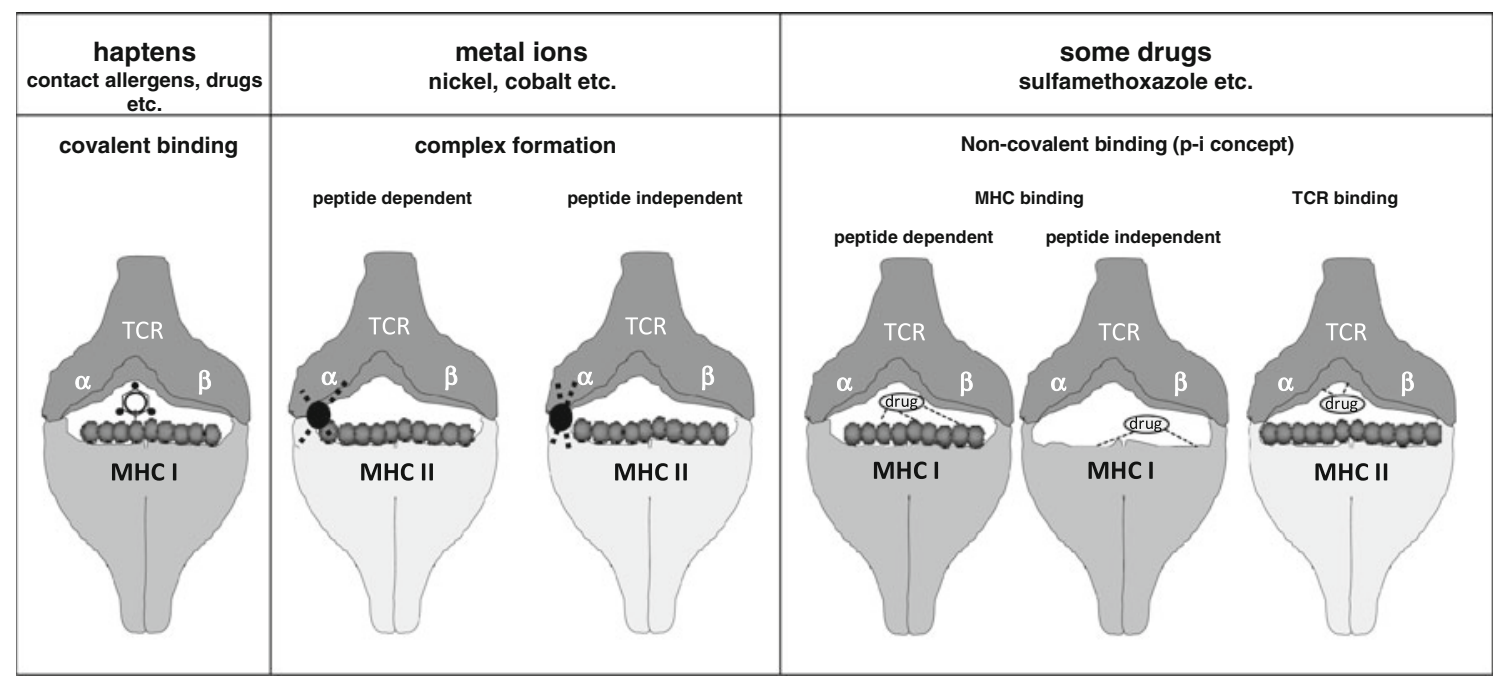

Fig. 1 Modes of chemical recognition by $\mathrm{T}$ cells. $\mathrm{T}$ cells interact with their TCR with MHC class I or class II molecules that present chemicals covalently bound to peptides in the binding groove of the MHC molecules (classical haptens), complexed to amino acids in
MHC molecules and TCR with or without participation of MHCbound peptides (metal ions) or noncovalently associated with MHC and/or TCR in a peptide-dependent or -independent manner ( $\mathrm{p}-\mathrm{i}$ concept, some drugs)
Table 1 Testable parameters addressed in T-cell assays

\begin{tabular}{lllll}
\hline & $\begin{array}{l}\text { Skin } \\
\text { penetration }\end{array}$ & $\begin{array}{l}\text { Chemical } \\
\text { reactivity }\end{array}$ & $\begin{array}{l}\text { Innate immune } \\
\text { activation }\end{array}$ & $\begin{array}{l}\text { T-cell } \\
\text { response }\end{array}$ \\
\hline Contact dermatitis & ++ & ++ & ++ & ++ \\
In vitro assays & & & + & ++ \\
Direct addition & -- & ++ & + & ++ \\
APC modification & -- & ++ & -- & ++ \\
Self-protein conjugates & -- & -- & & + \\
\hline
\end{tabular}

in the draining lymph nodes when DC that have been activated in the skin have immigrated and present chemicals to naive $\mathrm{T}$ cells. At present, the different protocols for in vitro assays completely neglect important aspects of the in vivo response to allergens that may contribute to allergenic potency. Among these are the efficiency of skin penetration, the metabolic capacity of skin cells to inactivate reactive chemicals or to generate reactive adducts from nonreactive chemicals, and the strength of chemical reactivity towards proteins. The latter point is not addressed, for example, when haptenated proteins are used as T-cell antigens. However, chemical reactivity seems to correlate with allergenic potency [40, 41]. Therefore, it is absolutely crucial to know the questions that can be addressed by the type of T-cell assay used (Table 1).

As for other, necessarily reductionist in vitro assays, a positive result in an in vitro $\mathrm{T}$-cell assay with a given chemical does not necessarily mean that this chemical will elicit a pathogenic T-cell response in vivo. Nevertheless, a positive result is a clear indication of a potential risk associated with the test compound due to its ability to prime $\mathrm{T}$ cells that may cause $\mathrm{ACD}$, respiratory allergies or ADR. Therefore, T-cell assays should significantly contribute to the refinement, reduction and eventual replacement of animal testing in this field of immunotoxicology and immunopharmacology.

The in vivo complexity of chemical-induced diseases as addressed in animal testing strategies has never been fully reproduced by currently available and developing in vitro testing strategies in toxicology. However, legislation requires the refinement, reduction and replacement of animal testing. Therefore, this problem can only be solved by continuous progress made in basic research using, for example, the contact hypersensitivity model $[18-20,24]$ to improve our still very incomplete understanding of the immunological pathomechanisms. From this research we have already identified and will identify key mechanisms and pathways that are being successfully incorporated in novel in vitro assays in immunotoxicology [17]. This will help to build a tiered strategy with a battery of assays that cover the different steps from sensitization to elicitation of chemical-induced disease [16, 17]. 
Past efforts using T cells in the study of immune responses to chemicals

In the 1990s the molecular basis for T-cell recognition of chemicals became clear [24-26]. Efforts were made to study primary human T-cell responses to chemicals. Different approaches were taken to induce T-cell responses to chemicals with respect to the populations of $\mathrm{T}$ cells and APC used, the means of application of the test chemicals and the cell culture protocols and readouts [42-51]. Table 2 summarizes the studies that have used protocols for priming of naive $\mathrm{T}$ cells with chemicals applied as shown in Fig. 2 and studies that have tested haptenated self-proteins as antigens for T-cell lines and clones from allergic patients [52-54]. Most protocols have used haptenmodified DC as APC and naive T cells as responder cells. Readout systems were T-cell proliferation and cytokine production. These studies demonstrated that it is possible to detect T-cell responses to chemicals in the naive repertoire, especially in the case of strong contact allergens such as 2,4,6-trinitrochlorobenzene (TNCB) that was mostly used in the form of the water-soluble derivative 2,4,6-trinitrobenzene sulphonic acid (TNBS) to directly modify APC. Moreover, they showed that memory T-cell responses can be analysed as well.

\section{State-of-the-art of T-cell assays}

Due to the scientific and technological developments in recent years, T-cell-based in vitro assays have improved. It is now possible to isolate highly pure and defined T-cell and APC populations by flow cytometric or magnetic bead separation technologies. Cytokines have been identified that upon addition to in vitro cultures help optimize T-cell responses. Improved protocols for the generation of different types and large numbers of DC have been developed and the knowledge of innate immune signals allows maturation and activation of DC in a suitable manner. Most protocols nowadays use monocyte-derived DC as APC and purified naive $T$ cells as responder cells. This excludes the presence of natural $\mathrm{CD} 4{ }^{+} \mathrm{CD} 25^{+} \mathrm{FOXP} 3^{+}$regulatory $\mathrm{T}$ cells (Treg) which may limit the extent of T-cell responses and prevent detection of responses to weakly immunogenic allergens or drugs [55]. Thus, the removal of Treg may significantly increase assay sensitivity [50].

Currently used readout systems are T-cell proliferation systems that use radioactive labelling or dilution of fluorochromes such as carboxyfluorescein succinimidyl ester. Moreover, T-cell activation markers have been identified that may be used to identify antigen-activated $\mathrm{T}$ cells. Examples are the TNF receptor family member CD137 (4-1BB) and the costimulatory molecule CD154 (CD40 ligand) which are induced specifically in antigen-activated
$\mathrm{T}$ cells and upregulated de novo on the cell surface [5658]. This allows the detection and isolation of antigenactivated $\mathrm{T}$ cells. In addition, techniques are now available that allow the detection of secreted or intracellular cytokines. The pairing of new laser technologies with new fluorochromes has led to the possibility of using multiparameter flow cytometry for the analysis of chemicaltriggered T-cell responses at the single-cell level [51].

The method of antigen delivery to T-cell assays is a critical point. Test chemicals can be added either directly to the assays or they can be used to modify APC or are added as hapten-protein conjugates (Fig. 2). These strategies are used to simulate the different effects of chemicals when they enter target tissues in vivo. Thus, chemical contact with the skin will result in direct interaction of the chemicals with cells. This will lead to the modification of membrane proteins on the cell surface and of intracellular proteins, and also to the direct modification of MHC-bound peptides. In addition, extracellular proteins will be modified to produce antigenic T-cell determinants when the haptenated proteins are taken up and processed by APC $[19,24]$.

The direct addition of chemicals to T-cell assays or the direct modification of APC can rarely be controlled with respect to the efficiency of chemical binding to cellular or extracellular proteins, the essential prerequisite for the induction of T-cell priming. In some cases there are hapten-specific antibodies that allow testing of productive cell surface modifications implicating the formation of T-cell epitopes. Without knowing whether a chemical has reacted with cellular or extracellular proteins, only a positive T-cell response is informative while a negative result cannot be interpreted. The latter may be caused by the failure of the chemical to react with proteins under in vitro culture conditions resulting in its inability to generate T-cell epitopes, or it may be due to the lack of $\mathrm{T}$ cells in the human or the individual donor's T-cell repertoire with specificity for that chemical. Therefore, the use of quality-controlled hapten-protein conjugates as antigens in T-cell assays has some advantages. The production of such conjugates requires that the chemical of interest binds covalently to or forms sufficiently stable complexes with a carrier protein. The reaction conditions can be adjusted to allow efficient coupling and adduct formation can be controlled by mass spectrometry. Ideally the carrier protein is a self-protein with absent or low immunogenicity.

Human serum albumin (HSA) is one of the carriers used in T-cell assays (Table 2). It is found in high concentrations in serum and in tissues such as skin. Hapten-protein conjugates must be taken up by APC and processed to hapten-modified peptides that can bind to MHC molecules. For the priming of $\mathrm{CD}^{+} \mathrm{T}$ cells the APC must be able to cross-present the hapten-modified peptides on MHC class I 


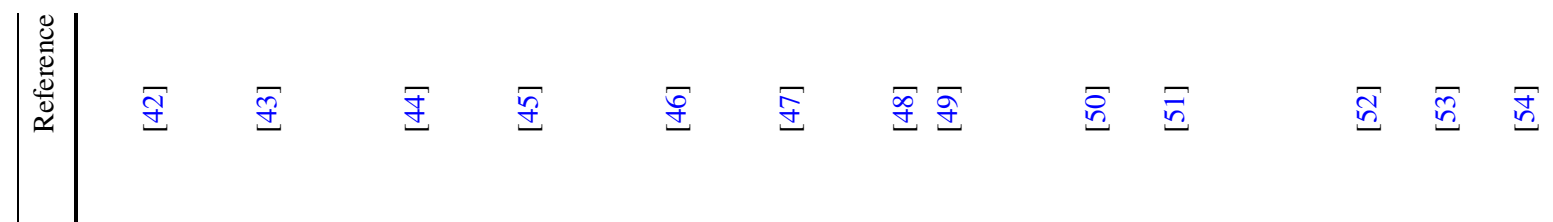

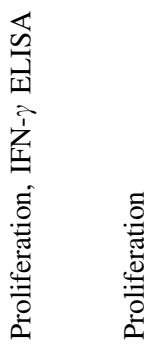

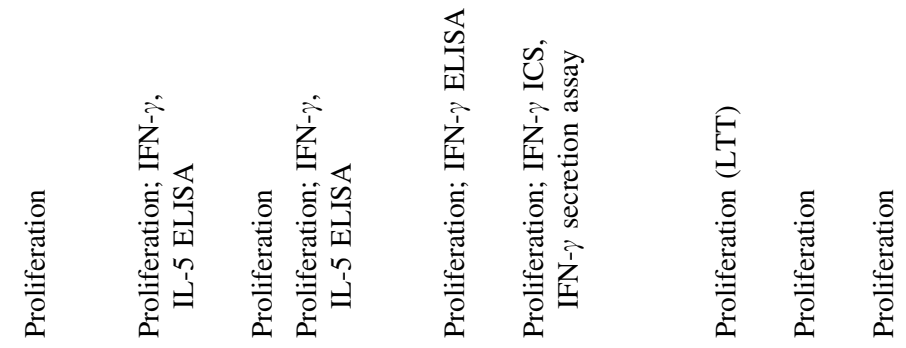

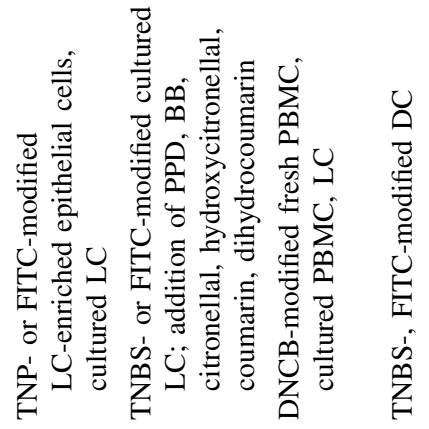

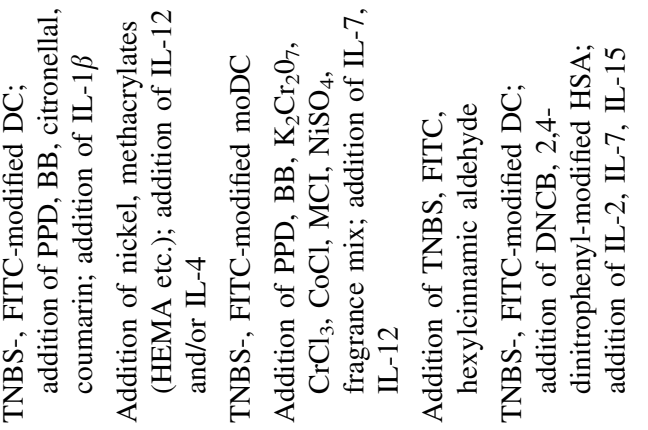

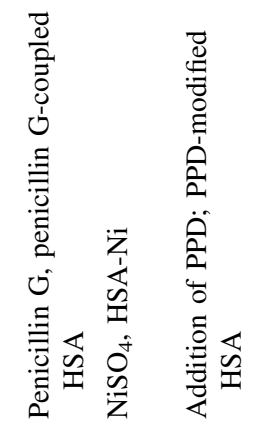
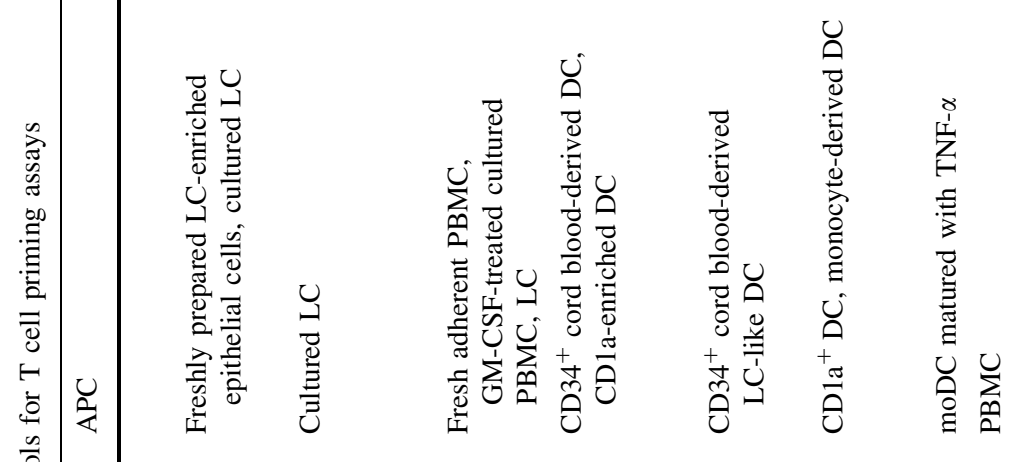

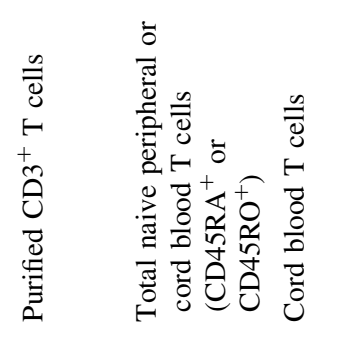

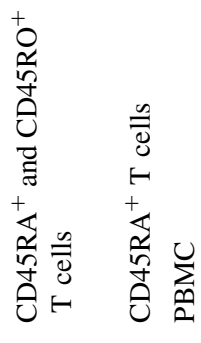

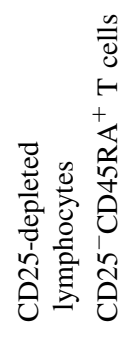

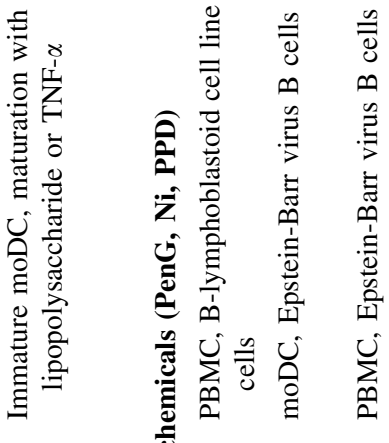

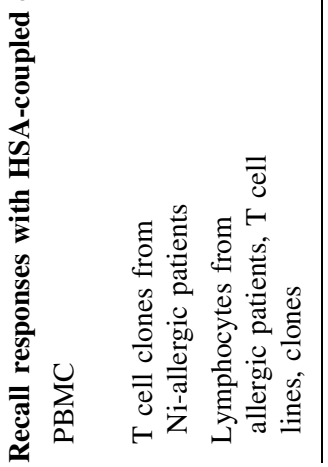



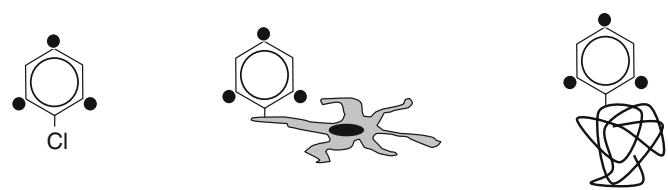

addition to culture hapten-modification of DC hapten-protein conjugates

Fig. 2 Modes of chemical delivery in T-cell assays. Chemicals that are used to stimulate $\mathrm{T}$ cells in T-cell assays can be either added directly or used to modify APC such as DC (hapten modification). Alternatively, chemical-coupled proteins (hapten-protein conjugates) such as HSA can be added to the T-cell/DC cocultures

molecules [59]. The production of such hapten-protein conjugates requires sufficient knowledge of the chemistry of the test compound. Buffer, $\mathrm{pH}$, and the molar ratios of chemical and protein are some of the factors that must be considered. The protein coupling and the degree of protein haptenation can be monitored using mass spectrometry. Here the mass shifts that are caused by chemical binding can be calculated by detection of adducts. Semiquantitative analysis yields information on the coupling efficiency [51, $54,60,61]$.

It has to be born in mind that the DC are activated in vivo in the tissue, for example the skin, directly by the protein-reactive chemical or indirectly by chemicalinduced danger signals. In the latter case these signals can be derived from other tissue cells or from the extracellular matrix $[18,19,62]$ with the consequence that this part of the immune response is missing in in vitro assays. Therefore, appropriate DC activation may be required for efficient in vitro priming of naive $\mathrm{T}$ cells (Table 1). In particular, when using hapten-protein conjugates, these signals are not given. Moreover, some of the chemicalinduced responses cannot be recapitulated in vitro due to tissue-derived danger signals $[18,19,62]$. Therefore, for optimal T-cell responses it may be crucial to provide these innate immune signals by adding proinflammatory cytokines such as TNF- $\alpha$ or ligands for Toll-like receptors such as lipopolysaccharide. One also has to consider that the timing and dosing of DC stimulation and antigen addition are critical with respect to the different capacities of immature versus mature DC to take up exogenous proteins such as hapten-protein conjugates.

Currently, two basic methods are used to prime naive human $\mathrm{T}$ cells with chemicals, drugs or protein allergens. The coculture of APC and T cells in the in vitro T-cell priming assay with chemicals induces primary $\mathrm{T}$-cell responses and the readout of secondary responses by restimulation with other control chemicals is used to ensure that antigen-specific T cells were primed (Fig. 3). A second method, the T-cell amplification method, introduces a primary polyclonal stimulation with a low starting number of $\mathrm{T}$ cells [63]. The idea is to amplify a low number of antigen-specific precursor $\mathrm{T}$ cells by polyclonal expansion several thousand fold and then interrogate this amplified T-cell pool by stimulation with the antigen of interest for antigen-specific $\mathrm{T}$ cells. While the former approach works with chemicals, the latter assay is reliable as readout for protein allergens. It allows determination of frequencies of antigen-specific $\mathrm{T}$ cells, both in the naive and the effector/ memory $\mathrm{T}$ cell pool. It remains to be tested whether this amplification method will work with hapten-protein conjugates.

\section{Meeting presentations}

Topic 1: chemical-reactive T cells

Philipp Esser (Freiburg) and Sonja Schmucker (BergischGladbach) presented the Sens-it-iv approach using the in vitro T-cell priming assay. Here, immature moDC are used to prime sorted naive $\mathrm{T}$ cells. It has been possible to prime naive human $\mathrm{T}$ cells with directly modified APC using TNBS and dinitrobenzene sulphonic acid. Proliferative responses were contact allergen-specific as demonstrated in secondary restimulations with haptenated DC. These

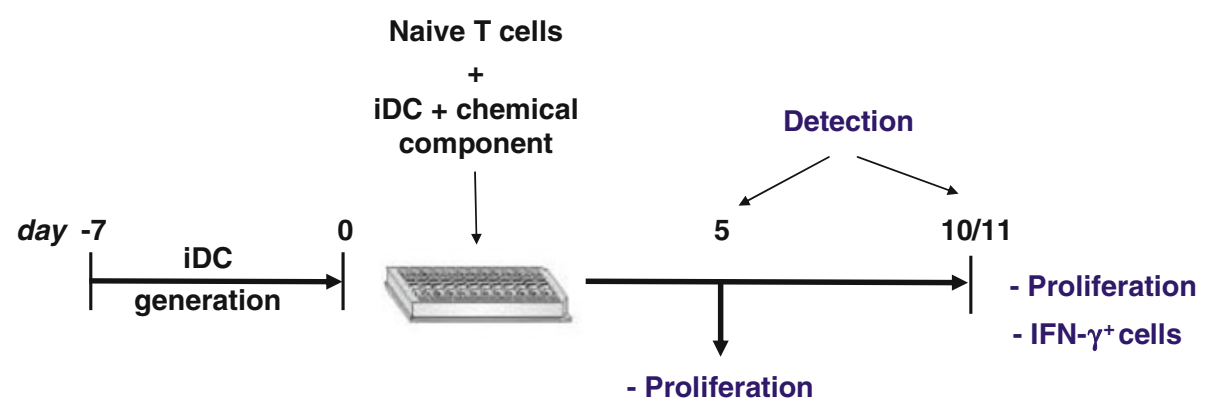

Fig. 3 Schematic protocol for in vitro T-cell priming assays. In the in vitro $\mathrm{T}$-cell priming assay, sorted naive human $\mathrm{T}$ cells are primed with immature DC plus chemical. Proliferation can be measured on days 5 and 10. The culture is restimulated with fresh DC plus

chemical on day 10 to assess antigen-specificity and to perform additional functional testing such as cytokine secretion assays or intracellular cytokine staining (ICS) 
results are also confirmed by the analysis of intracellular or secreted IFN- $\gamma$ by flow cytometry. The latter approach allows the detection and frequency analysis of antigenspecific $\mathrm{CD}^{+}{ }^{+}$and $\mathrm{CD}^{+} \mathrm{T}$ cells at the single-cell level. In addition, naive human $\mathrm{T}$ cells were primed with 2,4-dinitrophenyl-modified HSA fed to immature moDC that were then activated with the Toll-like receptor-4 agonist lipopolysaccharide [51]. Andrea Cavani (Rome) presented similar results obtained in the Sens-it-iv project. He showed that both direct conjugation of APC (mostly immature DC), and feeding APC with hapten-protein conjugates can induce specific $\mathrm{T}$-cell responses in vitro. However, there are some limitations. In the case of chemicals directly interacting with APC, toxicity, as measured by cell viability, is a major issue that limits optimal antigen concentrations with heavily lipophilic compounds. Most of the current assays use a cell viability greater than 75-80\%. Sonication of such compounds may help with selective chemicals such as squaric acid.

On the other hand, T-cell responsiveness to haptenprotein conjugates varies depending on the methodology used for the preparation of the conjugates, calling for strict standardization. This issue was addressed by HermannJosef Thierse (Mannheim) who showed how such haptenprotein conjugates can be produced, and the importance of physiologically related conditions such as $\mathrm{pH}$, modifiable amino acids and the type of chemical. He presented a mass spectrometry-based immunoproteomic approach for the identification of chemical modifications and outlined an approach that allows the degree of hapten modification of functionally active carrier proteins to be semiquantitatively determined and the type and site of modification to be identified [51]. Furthermore, interesting data were presented that were derived from this technology and modern proteomics to identify physiologically relevant target proteins that are hapten-modified in whole cells such as human keratinocytes and DC as well as in the skin. Surprisingly, only a limited number of proteins seem susceptible to hapten modification. Among the identified proteins are many that are associated with innate immune and stress responses as well as with antigen processing such as heat shock proteins [64-66]. Moreover, by applying recently established quantitative proteomic technologies to human skin cells, novel chemically regulated protein patterns have been discovered, which also may support the development of allergen-specific biomarkers in in vitro testing [64].

Marc Vocanson (Lyon) presented an alternative approach, developed in collaboration with COLIPA, the European trade association representing the interest of the cosmetics, toiletry and perfumery industry. He showed that cultivation of haptenated moDC with CD25 ${ }^{+}$Treg-depleted PBMC significantly increased hapten-specific T-cell priming against numerous contact allergens and, notably, weakly immunogenic allergens [50]. This indicates that Treg depletion increases the sensitivity of the assay. Thomas Rustemeyer (Amsterdam) presented data on in vitro T-cell priming by moDC. In this procedure moDC were also incubated with different contact allergens and cultured with autologous CD45RA ${ }^{+} \mathrm{T}$ cells in the presence of various cytokine cocktails [47, 49]. After 10-14 days T cells were divided into three aliquots and restimulated with medium alone, with the allergen used for priming or with a noncrossreacting or crossreacting contact allergen. Allergenspecific proliferation and cytokine production (i.e. IFN- $\gamma$ and IL-5) were found only in cultures restimulated with the allergen used for priming or with crossreacting compounds. In addition, loading of HLA A $2^{+}$-MUTZ- 3 cells with peptide antigens allowed the induction of specific proliferation.

Matthias Peiser (Berlin) proposed the contact allergenactivated $\mathrm{T}$ cell assay, a newly developed in vitro assay that detects the sensitizing potency of chemicals via DC-induced expression of lineage-specific T-cell transcription factors. After coculturing allergen-stimulated DC from the skin with T cells, polarization to specific subpopulations is analysed by expression of T-bet/IFN- $\gamma$, GATA3/IL-4, RORC2/IL-17 and FOXP3/IL-10 (data unpublished).

The loose-fit coculture-based sensitization assay (LCSA), developed by Reinhard Wanner (Berlin), is an alternative method to the mandatory LLNA (OECD test guideline 429) [14]. The sensitizing potential of chemicals is estimated according to detection of the biomarkers CD86, IL-6 and CCL4 by flow cytometry. This assay is unique among those involving DC differentiation in that the DC are generated from monocytes within a growing layer of primary keratinocytes [67, 68]. A panel of chemicals have already been tested and the LCSA was able to quantify the irritative and sensitizing potential within 5 days [69]. A comparison of half-maximal increases in mean fluorescence intensity for CD86 demonstrated concordance between the LCSA and LLNA for substances such as DNCB and PPD, which are categorized as extreme and strong, respectively. However, a few divergent classifications may reflect method-intrinsic differences in bioavailability between animal experiments (LLNA) and the barrier-free in vitro test (LCSA). In contrast to LLNA, the irritant sodium lauryl sulphate, weak sensitizers and nickel were correctly detected by the LCSA.

Topic 2: drug-reactive $\mathrm{T}$ cells

Dean Naisbitt (Liverpool) presented data on the characterization of antigenic determinants and the lessons learnt from drug allergy. Drugs and chemicals are thought to activate $\mathrm{T}$ cells by formation of reactive intermediates that bind covalently to protein. The paucity of studies that define protein adducts in patients has severely restricted 
mechanistic studies that relate chemistry to immune function. Thus, an improved understanding of T-cell responses to drugs and chemicals and subsequently the development of sensitive and specific T-cell assays to predict chemical sensitization requires a multidisciplinary scientific approach that relates compound distribution (including protein conjugation) to immune function. To do this, it is critical that tools are developed to define how haptens, compounds that interact directly with proteins, form T-cell stimulatory antigenic determinants. Several independent research groups have attempted to develop T-cell assays using soluble compounds, with limited success. The overriding problem is that the concentration required to achieve an antigenic threshold is often associated with a decrease in cell viability or loss of function. To overcome this issue, haptens can be delivered in a conjugated form (associated with either cellular or soluble protein). This approach has resulted in encouraging but often inconsistent data, which likely relates to the fact that methods to generate fully quantified protein adducts do not exist. To generate an antigenic determinant, one must consider absolute levels of binding, the stability of adducts (not all covalent bonds are irreversible) and the epitope profile (the number of sitespecific modifications).

Using state-of-the-art mass spectrometry and $\beta$-lactam antibiotics as model haptens, the Liverpool group has embarked upon a series of experiments to begin addressing this problem. Semiquantitative epitope profiling has revealed that $\beta$-lactams bind to a subset of lysine residues on proteins in a dose- and time-dependent manner, and display different preferences for the sites of modification. In vivo modification of albumin from flucloxacillinexposed patients has also been observed, with multisite modification being detected in each patient [70]. Reproducible, lymphocyte proliferative responses are detectable in allergic patients with drug-modified albumin, but only when the number of modifications exceeds a threshold.

The relationship between protein adduct formation and T-cell activation is even more complex with the drug metabolite hapten nitrososulphamethoxazole. Five structurally different protein adducts were characterized when nitrososulphamethoxazole was incubated with two proteins HSA and glutathione S-transferase $\pi$ [71]. The involvement of these complex and metastable haptenic structures in the stimulation of $\mathrm{T}$ cells has not been studied.

It is also important that future T-cell assays utilize cells from a large cohort of healthy volunteers. Recently, several strong genetic associations have been identified between expression of particular HLA molecules and susceptibility to specific forms of drug allergy [72-74]. Leading on from this, it was shown [75] that T-cell recognition of the reverse-transcriptase inhibitor abacavir is uniquely restricted by HLA-B*5701 and not closely related HLA molecules. It is possible that strong sensitizing chemicals such as the dinitro-halogenated benzenes overcome the absolute requirement for HLA restriction by the formation of multiple haptenic epitopes. However, this will not be the case for weak sensitizers, where the distribution of adducts formed will be more restricted.

Monika Keller (Bern) discussed strategies to improve in vitro tests for the diagnosis of ADR and for the detection of pre-existing sensitizations (risk assessment of drugs). Antigen-specific T lymphocytes can be detected in PBMCs by the measurement of proliferative responses (e.g. $\left[{ }^{3} \mathrm{H}\right]$ thymidine incorporation, carboxyfluorescein succinimidyl ester staining), the upregulation of activation markers (CD69, CD71, CD25, HLA-DR) and cytokine secretion (ELISA, ELISPOT, intracellular staining, bead assays), or by cytotoxicity assays.

The oldest test based on these principles is the "lymphocyte transformation/proliferation test" (LTT), which has a high specificity for drug-induced allergic reactions, but a poor sensitivity. It is suitable for testing different drug classes, and is even used for routine testing in drug hypersensitivities in some centres. But its practicability is limited (cells need to be cultured for 7 days, it involves radioactive labelling, human $\mathrm{AB}$ serum is the best culture additive, and it needs technical experience). Alternative in vitro tests are therefore of great interest. For CD69 upregulation, HSA can be used instead of $A B$ serum and cells need to be cultured for only 2-3 days [76]. Alternatively, as used in several studies, cytokines can be measured in the cell culture supernatant: the determination of IL-5 in PBMCs from ten patients with exanthema from amoxicillin showed a sensitivity of $92 \%$ and a specificity of $100 \%$ [77]. In another study, IFN- $\gamma$ was measured in 36 patients with cutaneous drug reactions [78] and showed a sensitivity of $78 \%$. Lochmatter et al. [79] measured 17 cytokines and chemokines in the cell culture supernatant using multiplex assays in five patients allergic to amoxicillin, five patients allergic to sulphonamides and five healthy controls. IL-2, IL-5, IFN- $\gamma$, IL-13 and TNF- $\alpha$ were increased most consistently among the 17 cytokines/chemokines measured. Thus, measuring different cytokines seems to improve the sensitivity of the test. These studies were all performed in patients with a clear history of ADR and positive LTTs or positive skin tests. Prospective studies with a larger number of patients and healthy controls are necessary to compare the sensitivity and specificity of the LTT, and CD69 and cytokine measurement.

The results of all in vitro tests are influenced by (a) the in vitro reactivity of the antigen/drug, (b) the frequency of drug-specific $\mathrm{T}$ cells, and (c) whether the reactive $\mathrm{T}$ cells are being detected appropriately by the test system chosen. The combination of different tests may increase the sensitivity. 
The detection of drug-specific $\mathrm{T}$ cells of sensitized, allergic patients is already a challenge and often fails. For the in vitro risk assessment of drugs a test is needed that detects the very low amount of pre-existing, i.e. naive, drugspecific $\mathrm{T}$ cells in healthy, drug-unexposed individuals, as currently developed for contact allergens. An improvement in the methods for the identification of the presumably rare drug-specific naive precursors is necessary. Preactivation of lymphocytes with cytokines (e.g. IL-7, IL-15, IL-2), polyclonal preactivation (e.g. with PHA), the costimulation with antibodies to costimulatory (anti-CD28, CD49d) or adhesion molecules (ICAM-1), the removal of Treg cells, the separate analysis of specific T-cell subsets, the use of DC as APC, the generation of T-cell lines, or prolonged T-cell cultures are only some ideas that might be evaluated. In some preliminary experiments modifying the LTT or the cytokine secretion experiments, it was possible to increase the (memory) responses to recall antigens but not to induce a naive T-cell response to small chemicals.

Enrico Maggi (Florence) discussed the potential use of drug-coupled carrier proteins for testing of drug crossreactivities. He reported data on the in vitro activity of a stable reagent formed by penicillin $\mathrm{G}$ active ester coupled with HSA (pen-HSA) on the PBMC of patients with a history of ADR to $\beta$-lactams (amoxicillin). In six (two with immediate and four with delayed ADR) out of ten patients this approach allowed the detection of a clinically manifest cross-reactivity between penicillin and amoxicillin that was not determined using the uncoupled drugs. The proliferative response to pen-HSA was HLA-restricted since it was abrogated by anti-class II HLA monoclonal antibodies. Notably, no proliferation was detectable with PBMC from ten non-allergic donors in response to pen-HSA or to the carrier alone. Thus, T-cell-based assays may also be of relevance for diagnostic purposes, e.g. to predict antibiotic cross-reactivities, and may allow a treatment regimen to be adapted to avoid drug cross-reactivity.

\section{Topic 3: protein allergens}

Federica Sallusto (Bellinzona) presented the T-cell amplification method [63]. In this assay rare antigen-specific precursor $\mathrm{T}$ cells from peripheral blood lymphocytes are amplified in vitro by polyclonal stimulation in replicate cultures. Each naive T cell is expanded several hundred- to a thousand-fold to clonal $\mathrm{T}$ cell blasts. These cultures are then stimulated with the antigen of interest allowing the identification of antigen-specific cultures via measurement of proliferation or cytokine production and, subsequently, the production of T-cell lines, clones and T-cell libraries. This method allows the assessment of the frequencies of antigen-specific precursors as well as of the TCR repertoire and has been used successfully with protein allergens. The method also works with memory T cells. The assay will be tested using for example HSA-coupled contact allergens and drugs. It may be very useful to increase the sensitivity of detection of T-cell responses especially in the case of low numbers of precursor $\mathrm{T}$ cells in the naive T-cell pool for a given chemical.

\section{Future perspectives}

The induction of a T-cell response by chemicals, drugs or protein allergens is the crucial step for the manifestation of allergic diseases and T-cell-mediated ADR. Therefore, it is important to further pursue the improvement in our methods to use $\mathrm{T}$ cells as valuable tools in immunotoxicology. Limitations are recognized and must be overcome where possible. One of the most obvious advantages is the clear distinction made by $\mathrm{T}$ cells between chemicals that form T-cell epitopes such as contact allergens, and irritants that cause toxic irritative inflammatory responses such as irritant contact dermatitis. Single-cell assays often fail to clearly differentiate between these types of chemicals due to an overlap in the mechanisms by which they trigger inflammation [80, 81].

One of the major drawbacks impeding the use of T-cellbased assays as high through-put test systems is the need to work with primary cells in an autologous setting. This causes donor to donor variations and requires testing of a sufficient number of different donors to yield statistically significant results and to exclude false results that may in part be due to differences in individual TCR repertoires. Moreover, the different properties of test chemicals, including their reactivity with proteins, toxicity and solubility, preclude in some cases the direct addition to cultures. Hapten-protein conjugates can overcome some of these problems, but the production of such quality-controlled reagents also prevents high throughput testing. Nevertheless, the T-cell readout is the ultimate test to predict allergenicity of chemicals or their potential to induce T-cell-mediated ADR. Since it is not likely that such assays will be a tool for the testing of large numbers of chemicals, they may be used as part of a tiered strategy [16] especially to test chemicals that fail to give unambiguous results in single cell-based assays that address innate immune mechanisms. Moreover, they can be used for chemicals that are of great interest for the cosmetics or pharmaceutical industry due to unique properties that are needed for a certain product. With the current technology it should then be possible to produce standardized haptenprotein conjugates for testing purposes.

A very important point that is key to comparing data obtained by different laboratories is the data evaluation. Standardization of the assays, harmonization of protocols and the definition of criteria for positive and negative 
results including suitable statistics is an urgent need. Performance standards have to be defined and the results obtained in the assays need to be compared with data from a LLNA [82, 83] and with clinical experience with known test compounds. A sufficient number of known compounds have to be tested in a combined effort and ring trials will be performed on a limited set of these compounds to assess the robustness and transferability of the assay technology. It remains to be seen whether such assays are suitable for determining the allergenic potency as can be done with the LLNA. Moreover, data reporting has not yet been standardized, but establishing publication guidelines, as recently proposed for $\mathrm{T}$ cell-based immune monitoring strategies [84], will enable comparison of data from different laboratories.

The current problem is that the field is still in the exploratory phase. Assays are still being refined, protocols are being modified and new data from basic research are being incorporated, one example being the identification of new T-cell subsets and T-cell plasticity that impacts, for example, on the cytokine readout [85]. Nevertheless, such expert meetings should be held on a regular basis in the future in order to achieve our goal. It is clear that knowledge of the chemistry is required to perform and refine T-cell-based assays, and that this involves close collaborations with chemists possessing this expertise. Historical data are available and more experience is gained with the development of assays that are based on the chemical reactivity to peptides [40, 41]. It remains an open and difficult question whether and how T-cell-based assays can incorporate pre- and pro-haptens [86, 87].

\section{Conclusion}

In summary, T-cell-based assays, despite their obvious complexity and limitations, are a useful and valid tool in immunotoxicology. They support predictive hazard identification and risk assessment and will complement other assays that are based on single cells, e.g. DC or keratinocytes, and address the induction of innate immune responses as measured, for example, by chemical-induced cytokine production or expression of activation markers on these cells [17]. The recent major improvements in the T-cell assay protocols include the removal of immunoregulatory cells which significantly increases the sensitivity of the assays [50]. This has been shown in mice where contact hypersensitivity responses to weak contact allergens were only induced when all $\mathrm{CD}^{+} \mathrm{T}$ cells were depleted before sensitization [88-90]. In addition sensitive detection methods allow amplification of weak T-cell responses by polyclonal expansion of precursors [63] and the multiparametric analysis of single cells using flow cytometric detection of cell surface markers including those that indicate antigen-specific activation and intracellular cytokines [51, 56-58]. These technologies allow isolation of live antigen-specific cells for the generation of $\mathrm{T}$-cell clones and for the determination of frequencies of allergen- and drug-specific $T$ cells and of the diversity of the TCR repertoire. Since T-cell assays address the adaptive immune response that is crucial for the development of chemical-induced disease, they provide the ultimate answer to the question whether an unknown chemical has the potential to induce contact or respiratory allergies or ADR. Thus, we are convinced that T-cell assays will contribute to the efforts to reduce and eventually replace animal testing. This is still a difficult task given that in vitro assays must be able to guarantee the safety of consumer products and drugs [91].

Acknowledgments We acknowledge the support for the Expert Meeting by the European Commission as part of the project "Novel Testing Strategies for In Vitro Assessment of Allergens (Sens-it-iv)", LSHB-CT-2005-018681.

Conflict of interest The authors declare that there are no conflicts of interest.

\section{References}

1. European Commission (2003) Directive 2003/15/EC of the European parliament and of the council of 27 February 2003 amending council directive 76/768/EEC on the approximation of the laws of the member states relating to cosmetic products (7th Amendment to the European cosmetics directive). Official J Eur Union, L 66:26-35

2. Basketter DA, Kimber I (2009) Updating the skin sensitization in vitro data assessment paradigm in 2009. J Appl Toxicol 29:545-550

3. Basketter DA, McFadden JF, Gerberick F, Cockshott A, Kimber I (2009) Nothing is perfect, not even the local lymph node assay: a commentary and the implications for REACH. Contact Dermatitis 60:65-69

4. European Commission (2006) Regulation (EC) No 1907/2006 of the European Parliament and of the Council of 18 December 2006 concerning the Registration, Evaluation, Authorisation and restriction of Chemicals (REACH), establishing a European Chemicals Agency, amending Directive 1999/45/EC and repealing Council Regulation (EEC) No 793/93 and Commission Regulation (EC) No 1488/94 as well as Council Directive 76/769/ EEC and Commission Directives 91/155/EEC, 93/67/EEC, 93/ 105/EC and 2000/21/EC. Official J Eur Union L 396:1-849

5. Hartung T, Rovida C (2009) Chemical regulators have overreached. Nature 460:1080-1081

6. Rovida C, Hartung T (2009) Re-evaluation of animal numbers and costs for in vivo tests to accomplish REACH legislation requirements for chemicals - a report by the transatlantic think tank for toxicology. ALTEX 26:187-208

7. Gilbert N (2010) Streamlined chemical tests rebuffed. Nature 463:142-143

8. Collins FS, Gray GM, Bucher JR (2008) Transforming environmental health protection. Science 319:906-907 
9. National Institute of Environmental Health Sciences (2008) Memorandum of Understanding on High Throughput Screening, Toxicity Pathway Profiling, and Biological Interpretation of Findings. http://www.niehs.nih.gov/news/releases/2008/docs/ ntpncgcepamou.pdf. Accessed 11 August 2010

10. National Academy of Sciences (2007) Toxicity Testing in the 21st Century: A Vision and a Strategy. The National Academies Press, Washington, DC

11. European Commission (2007) Fifth Report from the Commission to the Council and the European Parliament on the Statistics on the number of animals used for experimental and other scientific purposes in the member states of the European Union. http://ec. europa.eu/environment/chemicals/lab_animals/reports_en.htm

12. Höfer T, Gerner I, Gundert-Remy U, Liebsch M, Schulte A, Spielmann H, Vogel R, Wettig K (2004) Animal testing and alternative approaches for the human health risk assessment under the proposed new European Chemicals Regulation. Arch Toxicol 78:549-564

13. Van der Jagt K, Munn S, Torslov J, de Bruijn J (2004) Alternative approaches can reduce the use of test animals under REACH. European Commission, Joint Research Centre. http://ecb.jrc.ec. europa.eu/documents/REACH/PUBLICATIONS/Reducing_the_ use_of_test_animals_under_REACH_IHCP_report.pdf

14. OECD (2008) Guidelines for the Testing of Chemicals. http://titania.sourceoecd.org/vl=1849270/cl=12/nw=1/rpsv/cw/ vhosts/oecdjournals/1607310x/v1n4/contp1-1.htm

15. European Commission (2007) REACH - Registration, Evaluation, Authorisation and Restriction of Chemicals. http://ec. europa.eu/enterprise/reach/index_en.htm. Accessed 1 June 2007

16. Jowsey IR, Basketter DA, Westmoreland C, Kimber I (2006) A future approach to measuring relative skin sensitising potency: a proposal. J Appl Toxicol 26:341-350

17. dos Santos GG, Reinders J, Ouwehand K, Rustemeyer T, Scheper RJ, Gibbs S (2009) Progress on the development of human in vitro dendritic cell based assays for assessment of the sensitizing potential of a compound. Toxicol Appl Pharmacol 236:372-382

18. Martin SF (2010) The role of the innate immune system in allergic contact dermatitis. Allergologie 33:66-70

19. Freudenberg MA, Esser PR, Jakob T, Galanos C, Martin SF (2009) Innate and adaptive immune responses in contact dermatitis: analogy with infections. G Ital Dermatol Venereol 144:173-185

20. Martin SF, Jakob T (2008) From innate to adaptive immune responses in contact hypersensitivity. Curr Opin Allergy Clin Immunol 8:289-293

21. Natsch A, Emter R (2008) Skin sensitizers induce antioxidant response element dependent genes: application to the in vitro testing of the sensitization potential of chemicals. Toxicol Sci 102:110-119

22. Emter R, Ellis G, Natsch A (2010) Performance of a novel keratinocyte-based reporter cell line to screen skin sensitizers in vitro. Toxicol Appl Pharmacol 245:281-290

23. Corsini E, Mitjans M, Galbiati V, Lucchi L, Galli CL, Marinovich M (2009) Use of IL-18 production in a human keratinocyte cell line to discriminate contact sensitizers from irritants and low molecular weight respiratory allergens. Toxicol In Vitro 23:789-796

24. Martin SF (2004) T lymphocyte-mediated immune responses to chemical haptens and metal ions: implications for allergic and autoimmune disease. Int Arch Allergy Immunol 134:186-198

25. Thierse HJ, Gamerdinger K, Junkes C, Guerreiro N, Weltzien HU (2005) T cell receptor (TCR) interaction with haptens: metal ions as non-classical haptens. Toxicology 209:101-107

26. Posadas SJ, Pichler WJ (2007) Delayed drug hypersensitivity reactions - new concepts. Clin Exp Allergy 37:989-999

27. Ortmann B, Martin S, von Bonin A, Schiltz E, Hoschutzky H, Weltzien HU (1992) Synthetic peptides anchor T cell-specific TNP epitopes to MHC antigens. J Immunol 148:1445-1450
28. Martin S, Ortmann B, Pflugfelder U, Birsner U, Weltzien HU (1992) Role of hapten-anchoring peptides in defining haptenepitopes for MHC-restricted cytotoxic $\mathrm{T}$ cells. Cross-reactive TNP-determinants on different peptides. J Immunol 149:25692575

29. Martin S, von Bonin A, Fessler C, Pflugfelder U, Weltzien HU (1993) Structural complexity of antigenic determinants for class I MHC-restricted, hapten-specific $\mathrm{T}$ cells. Two qualitatively differing types of $\mathrm{H}-2 \mathrm{~Kb}$-restricted TNP epitopes. J Immunol 151:678-687

30. von Bonin A, Ortmann B, Martin S, Weltzien HU (1992) Peptideconjugated hapten groups are the major antigenic determinants for trinitrophenyl-specific cytotoxic T cells. Int Immunol 4:869-874

31. Kohler J, Martin S, Pflugfelder U, Ruh H, Vollmer J, Weltzien HU (1995) Cross-reactive trinitrophenylated peptides as antigens for class II major histocompatibility complex-restricted $\mathrm{T}$ cells and inducers of contact sensitivity in mice. Limited $\mathrm{T}$ cell receptor repertoire. Eur J Immunol 25:92-101

32. Padovan E, Bauer T, Tongio MM, Kalbacher H, Weltzien HU (1997) Penicilloyl peptides are recognized as T cell antigenic determinants in penicillin allergy. Eur J Immunol 27:1303-1307

33. Lu L, Vollmer J, Moulon C, Weltzien HU, Marrack P, Kappler J (2003) Components of the ligand for a $\mathrm{Ni}(++)$ reactive human $\mathrm{T}$ cell clone. J Exp Med 197:567-574

34. Gamerdinger K, Moulon C, Karp DR, Van Bergen J, Koning F, Wild D, Pflugfelder U, Weltzien HU (2003) A new type of metal recognition by human $\mathrm{T}$ cells: contact residues for peptideindependent bridging of $\mathrm{T}$ cell receptor and major histocompatibility complex by nickel. J Exp Med 197:1345-1353

35. Schnyder B, Mauri-Hellweg D, Zanni M, Bettens F, Pichler WJ (1997) Direct, MHC-dependent presentation of the drug sulfamethoxazole to human alphabeta $\mathrm{T}$ cell clones. J Clin Invest 100:136-141

36. Zanni MP, von Greyerz S, Schnyder B, Wendland T, Pichler WJ (1998) Allele-unrestricted presentation of lidocaine by HLA-DR molecules to specific alphabeta+ $\mathrm{T}$ cell clones. Int Immunol 10:507-515

37. Zanni MP, von Greyerz S, Schnyder B, Brander KA, Frutig K, Hari Y, Valitutti S, Pichler WJ (1998) HLA-restricted, processing- and metabolism-independent pathway of drug recognition by human alpha beta T lymphocytes. J Clin Invest 102:1591-1598

38. von Greyerz S, Zanni MP, Frutig K, Schnyder B, Burkhart C, Pichler WJ (1999) Interaction of sulfonamide derivatives with the TCR of sulfamethoxazole-specific human alpha beta+ $\mathrm{T}$ cell clones. J Immunol 162:595-602

39. Castrejon JL, Berry N, El Ghaiesh S, Gerber PichlerWJ, Park BK, Naisbitt DJ (2010) Stimulation of human T cells with sulfonamides and sulfonamide metabolites. J Allergy Clin Immunol 125:411-418

40. Gerberick GF, Vassallo JD, Foertsch LM, Price BB, Chaney JG, Lepoittevin JP (2007) Quantification of chemical peptide reactivity for screening contact allergens: a classification tree model approach. Toxicol Sci 97:417-427

41. Gerberick GF, Aleksic M, Basketter D, Casati S, Karlberg AT, Kern P, Kimber I, Lepoittevin JP, Natsch A, Ovigne JM, Rovida C, Sakaguchi H, Schultz T (2008) Chemical reactivity measurement and the predictive identification of skin sensitisers. The report and recommendations of ECVAM Workshop 64. Altern Lab Anim 36:215-242

42. Moulon C, Peguet-Navarro J, Courtellemont P, Redziniak G, Schmitt D (1993) In vitro primary sensitization and restimulation of hapten-specific $\mathrm{T}$ cells by fresh and cultured human epidermal Langerhans' cells. Immunology 80:373-379

43. Krasteva M, Peguet-Navarro J, Moulon C, Courtellemont P, Redziniak G, Schmitt D (1996) In vitro primary sensitization of hapten-specific $\mathrm{T}$ cells by cultured human epidermal Langerhans 
cells - a screening predictive assay for contact sensitizers. Clin Exp Allergy 26:563-570

44. Dai R, Streilein JW (1998) Naive, hapten-specific human T lymphocytes are primed in vitro with derivatized blood mononuclear cells. J Invest Dermatol 110:29-33

45. Rougier N, Redziniak G, Schmitt D, Vincent C (1998) Evaluation of the capacity of dendritic cells derived from cord blood CD34+ precursors to present haptens to unsensitized autologous $\mathrm{T}$ cells in vitro. J Invest Dermatol 110:348-352

46. Rougier N, Redziniak G, Mougin D, Schmitt D, Vincent C (2000) In vitro evaluation of the sensitization potential of weak contact allergens using Langerhans-like dendritic cells and autologous T cells. Toxicology 145:73-82

47. Rustemeyer T, De Ligter S, von Blomberg BM, Frosch PJ, Scheper RJ (1999) Human T lymphocyte priming in vitro by haptenated autologous dendritic cells. Clin Exp Immunol 117:209-216

48. Guironnet G, Dalbiez-Gauthier C, Rousset F, Schmitt D, PeguetNavarro J (2000) In vitro human T cell sensitization to haptens by monocyte-derived dendritic cells. Toxicol In Vitro 14:517-522

49. Moed H, von Blomberg M, Bruynzeel DP, Scheper R, Gibbs S, Rustemeyer $T$ (2005) Improved detection of allergen-specific $\mathrm{T}$-cell responses in allergic contact dermatitis through the addition of 'cytokine cocktails'. Exp Dermatol 14:634-640

50. Vocanson M, Cluzel-Tailhardat M, Poyet G, Valeyrie M, Chavagnac C, Levarlet B, Courtellemont P, Rozieres A, Hennino A, Nicolas JF (2008) Depletion of human peripheral blood lymphocytes in CD25+ cells allows for the sensitive in vitro screening of contact allergens. J Invest Dermatol 128:2119-2122

51. Dietz L, Esser PR, Schmucker, S, Goette I, Richter A, Schnöelzer M, Martin SF, Thierse HJ (2010) Tracking human contact allergens: from mass spectrometric identification of peptide-bound reactive small chemicals to chemical-specific naive human $\mathrm{T}$ cell priming. Toxicol Sci. DOI: 10.1093/toxsci/kfq209

52. Brander C, Mauri-Hellweg D, Bettens F, Rolli H, Goldman M, Pichler WJ (1995) Heterogeneous T cell responses to beta-lactam-modified self-structures are observed in penicillin-allergic individuals. J Immunol 155:2670-2678

53. Thierse HJ, Moulon C, Allespach Y, Zimmermann B, Doetze A, Kuppig S, Wild D, Herberg F, Weltzien HU (2004) Metal-protein complex-mediated transport and delivery of $\mathrm{Ni} 2+$ to TCR/MHC contact sites in nickel-specific human T cell activation. J Immunol 172:1926-1934

54. Jenkinson C, Jenkins RE, Aleksic M, Pirmohamed M, Naisbitt DJ, Park BK (2010) Characterization of p-phenylenediaminealbumin binding sites and T-cell responses to hapten-modified protein. J Invest Dermatol 130:732-742

55. Curotto de Lafaille MA, Lafaille JJ (2009) Natural and adaptive foxp3+ regulatory $\mathrm{T}$ cells: more of the same or a division of labor? Immunity 30:626-635

56. Frentsch M, Arbach O, Kirchhoff D, Moewes B, Worm M, Rothe M, Scheffold A, Thiel A (2005) Direct access to CD4+ T cells specific for defined antigens according to CD154 expression. Nat Med 11:1118-1124

57. Wolfl M, Kuball J, Ho WY, Nguyen H, Manley TJ, Bleakley M, Greenberg PD (2007) Activation-induced expression of CD137 permits detection, isolation, and expansion of the full repertoire of $\mathrm{CD} 8+\mathrm{T}$ cells responding to antigen without requiring knowledge of epitope specificities. Blood 110:201-210

58. Wehler TC, Karg M, Distler E, Konur A, Nonn M, Meyer RG, Huber C, Hartwig UF, Herr W (2008) Rapid identification and sorting of viable virus-reactive $\mathrm{CD} 4(+)$ and $\mathrm{CD} 8(+) \mathrm{T}$ cells based on antigen-triggered CD137 expression. J Immunol Methods 339:23-37

59. Burgdorf S, Kurts C (2008) Endocytosis mechanisms and the cell biology of antigen presentation. Curr Opin Immunol 20:89-95
60. Aleksic M, Thain E, Roger D, Saib O, Davies M, Li J, Aptula A, Zazzeroni R (2009) Reactivity profiling: covalent modification of single nucleophile peptides for skin sensitization risk assessment. Toxicol Sci 108:401-411

61. Aleksic M, Pease CK, Basketter DA, Panico M, Morris HR, Dell A (2007) Investigating protein haptenation mechanisms of skin sensitisers using human serum albumin as a model protein. Toxicol In Vitro 21:723-733

62. Martin SF, Dudda JC, Bachtanian E, Lembo A, Liller S, Durr C, Heimesaat MM, Bereswill S, Fejer G, Vassileva R, Jakob T, Freudenberg N, Termeer CC, Johner C, Galanos C, Freudenberg MA (2008) Toll-like receptor and IL-12 signaling control susceptibility to contact hypersensitivity. J Exp Med 205:2151-2162

63. Geiger R, Duhen D, Lanzavecchia A, Sallusto F (2009) Human naive and memory $\mathrm{CD} 4+\mathrm{T}$ cell repertoires specific for naturally processed antigens analyzed using libraries of amplified $\mathrm{T}$ cells. J Exp Med 206:1525-1534

64. Heiss K, Junkes C, Guerreiro N, Swamy M, Camacho-Carvajal MM, Schamel WW, Haidl ID, Wild D, Weltzien HU, Thierse HJ (2005) Subproteomic analysis of metal-interacting proteins in human B cells. Proteomics 5:3614-3622

65. Martin SF, Merfort I, Thierse H-J (2006) Interactions of chemicals and metal ions with proteins and role for immune responses. Mini Rev Med Chem 6:247-255

66. Dietz L, Bosque A, Pankert P, Ohnesorge S, Merz P, Anel A, Schnölzer M, Thierse HJ (2009) Quantitative DY-maleimidebased proteomic 2-DE-labeling strategies using human skin proteins. Proteomics 9:4298-4308

67. Schreiner M, Peiser M, Briechle D, Stahlmann R, Zuberbier T, Wanner R (2007) A loose-fit coculture of activated keratinocytes and dendritic cell-related cells for prediction of sensitizing potential. Allergy 62:1419-1428

68. Schreiner M, Peiser M, Briechle D, Stahlmann R, Zuberbier T, Wanner R (2008) A new dendritic cell type suitable as sentinel of contact allergens. Toxicology 249:146-152

69. Wanner R, Sonnenburg A, Quatchadze M, Schreiner M, Peiser M, Zuberbier T, Stahlmann R (2010) Classification of sensitizing and irritative potential in a combined in vitro assay. Toxicol Appl Pharmacol 245:211-218

70. Jenkins RE, Meng X, Elliott VL, Kitteringham NR, Pirmohamed M, Park K (2009) Characterisation of flucloxacillin and 5-hydroxymethyl flucloxacillin haptenated HSA in vitro and in vivo. Proteomics Clin Appl 3:720-729

71. Callan HE, Jenkins RE, Maggs JL, Lavergne SN, Clarke SE, Naisbitt DJ, Park BK (2009) Multiple adduction reactions of nitroso sulfamethoxazole with cysteinyl residues of peptides and proteins: implications for hapten formation. Chem Res Toxicol 22:1172-1180

72. Mallal S, Nolan D, Witt C, Masel G, Martin AM, Moore C, Sayer D, Castley A, Mamotte C, Maxwell D, James I, Christiansen FT (2002) Association between presence of HLA-B*5701, HLADR7, and HLA-DQ3 and hypersensitivity to HIV-1 reversetranscriptase inhibitor abacavir. Lancet 359:727-732

73. Daly AK, Donaldson PT, Bhatnagar P, Shen Y, Pe'er I, Floratos A, Daly MJ, Goldstein DB, John S, Nelson MR, Graham J, Park BK, Dillon JF, Bernal W, Cordell HJ, Pirmohamed M, Aithal GP, Day CP (2009) HLA-B*5701 genotype is a major determinant of drug-induced liver injury due to flucloxacillin. Nat Genet 41:816-819

74. Chung WH, Hung SI, Hong HS, Hsih MS, Yang LC, Ho HC, Wu JY, Chen YT (2004) Medical genetics: a marker for StevensJohnson syndrome. Nature 428:486

75. Chessman D, Kostenko L, Lethborg T, Purcell AW, Williamson NA, Chen Z, Kjer-Nielsen L, Mifsud NA, Tait BD, Holdsworth R, Almeida CA, Nolan D, Macdonald WA, Archbold JK, Kellerher AD, Marriott D, Mallal S, Bharadwaj M, Rossjohn J, 
McCluskey J (2008) Human leukocyte antigen class I-restricted activation of CD8 $+\mathrm{T}$ cells provides the immunogenetic basis of a systemic drug hypersensitivity. Immunity $28: 822-832$

76. Beeler A, Zaccaria L, Kawabata T, Gerber BO, Pichler WJ (2008) CD69 upregulation on T cells as an in vitro marker for delayed-type drug hypersensitivity. Allergy 63:181-188

77. Sachs B, Erdmann S, Baron JM, Neis M, Al Masaoudi T, Merk HF (2002) Determination of interleukin-5 secretion from drugspecific activated ex vivo peripheral blood mononuclear cells as a test system for the in vitro detection of drug sensitization. Clin Exp Allergy 32:736-744

78. Halevy S, Cohen AD, Grossman N (2005) Clinical implications of in vitro drug-induced interferon gamma release from peripheral blood lymphocytes in cutaneous adverse drug reactions. J Am Acad Dermatol 52:254-261

79. Lochmatter P, Beeler A, Kawabata TT, Gerber BO, Pichler WJ (2009) Drug-specific in vitro release of IL-2, IL-5, IL-13 and IFN-gamma in patients with delayed-type drug hypersensitivity. Allergy 64:1269-1278

80. Ryan CA, Gildea LA, Hulette BC, Dearman RJ, Kimber I, Gerberick GF (2004) Gene expression changes in peripheral blood-derived dendritic cells following exposure to a contact allergen. Toxicol Lett 150:301-316

81. Gildea LA, Ryan CA, Foertsch LM, Kennedy LM, Dearman RJ, Kimber I, Gerberick GF (2006) Identification of gene expression changes induced by chemical allergens in dendritic cells: opportunities for skin sensitization testing. J Invest Dermatol 126:1813-1822

82. Gerberick GF, Ryan CA, Kern PS, Schlatter H, Dearman RJ, Kimber I, Patlewicz GY, Basketter DA (2005) Compilation of historical local lymph node data for evaluation of skin sensitization alternative methods. Dermatitis 16:157-202

83. Kern PS, Gerberick GF, Ryan CA, Kimber I, Aptula A, Basketter DA (2010) Local lymph node data for the evaluation of skin sensitization alternatives: a second compilation. Dermatitis 21:8-32

84. Janetzki S, Britten CM, Kalos M, Levitsky HI, Maecker HT, Melief CJ, Old LJ, Romero P, Hoos A, Davis MM (2009) "MIATA" - minimal information about $\mathrm{T}$ cell assays. Immunity 31:527-528

85. O'Shea JJ, Paul WE (2010) Mechanisms underlying lineage commitment and plasticity of helper CD4+ T cells. Science 327:1098-1102

86. Merk HF, Baron J, Neis MM, Obrigkeit DH, Karlberg AT (2007) Skin: major target organ of allergic reactions to small molecular weight compounds. Toxicol Appl Pharmacol 224:313-317

87. Karlberg AT, Bergstrom MA, Borje A, Luthman K, Nilsson JL (2008) Allergic contact dermatitis - formation, structural requirements, and reactivity of skin sensitizers. Chem Res Toxicol 21:53-69

88. Vocanson M, Hennino A, Cluzel-Tailhardat M, Saint-Mezard P, Benetiere J, Chavagnac C, Berard F, Kaiserlian D, Nicolas JF (2006) CD8+ T cells are effector cells of contact dermatitis to common skin allergens in mice. J Invest Dermatol 126:815-820

89. Lass C, Vocanson M, Wagner S, Schempp CM, Nicolas JF, Merfort I, Martin SF (2008) Anti-inflammatory and immune regulatory mechanisms prevent contact hypersensitivity to Arnica montana L. Exp Dermatol 17:849-857

90. Vocanson M, Hennino A, Rozieres A, Cluzel-Tailhardat M, Poyet G, Valeyrie M, Benetiere J, Tedone R, Kaiserlian D, Nicolas JF (2009) Skin exposure to weak and moderate contact allergens induces IFNgamma production by lymph node cells of CD4+ T-cell-depleted mice. J Invest Dermatol 129:1185-1191

91. Weltzien HU, Corsini E, Gibbs S, Borrebaeck C, Budde P, Thierse HJ, Martin SF, Roggen EL (2009) Safe cosmetics without animal testing? Contributions of the EU Project Sens-it-iv. J Verbr Lebensm 4(Suppl. II):S41-S48 